\title{
Formation of Granular Deposits on Platinum Electrode during Potentiometric Titration of Hexadecyltrithiocarbonate
}

\author{
T. RAJU ${ }^{\mathrm{a}^{*}}, \mathrm{~K}$. GIRIBABU ${ }^{\mathrm{a}}$ and V. NARAYANAN ${ }^{\mathrm{b}}$
}

${ }^{a}$ Department of Analytical Chemistry, Guindy Maraimalai Campus, University of Madras, Chennai - 600 025, India

${ }^{\mathrm{b}}$ Department of Inorganic Chemistry, Guindy Maraimalai Campus, University of Madras, Chennai - 600 025, India

proftraju2004@yahoo.com

Received 19 January 2013 / Accepted 15 February 2013

\begin{abstract}
In this work, we report the formation of multilayers on the platinum electrode during the potentiometric titration of hexadecyltrithiocarbonate (HDTTC) with mercuric ions. The titration was carried out using universal buffer as the buffering agent in order to study the influence of the $\mathrm{pH}$ on the titrimetric analysis. Moreover, various concentrations of sodium acetate and sodium carbonate were employed to find out the effect of the ionic strength on the titrimetric analysis. In case of universal buffer, in lower $\mathrm{pH}$ (8-11) the recoveries of HDTTC were found to be $150 \%$, which is an indicative of the formation of polynuclear complex. The formed deposits were studied by using scanning electron microscope (SEM) and elemental diffaraction analysis by X-rays (EDAX). An attempt was made to explain the formation of multilayers on to the platinum electrode.
\end{abstract}

Keywords: Multilayers, SEM, Potentiometric titrations, Platinum electrode

\section{Introduction}

Trithiocarbonates (TTC) belongs to the family of sulphur compounds, the other congener were xanthates, dithocarbamates, dithiophosphates, dixanthogen etc., Trithiocarbonates were used as floatation agents and as a precursor in synthesis of metal sulphides ${ }^{1-7}$. The studies on TTC were scarce in literature. TTC complexes closely resembles the xanthates in all aspects in the possession of hetero atom ' $\mathrm{S}$ ' atom in place of ' $\mathrm{O}$ ' present in case of xanthate. Transisition metal complexes of many mono anionic 1,1- dithiolates have been prepared and studied. The complexes of alkyl TTC were reported by Scshaeffer ${ }^{8}$. However, the chemical properties of these compounds were not discussed. Later, Ewald and Sinn reported the isolation of several thioxanthate complexs of $\mathrm{Ni}(\mathrm{II}), \mathrm{Cu}(\mathrm{II}), \mathrm{Co}(\mathrm{III})$ and $\mathrm{Fe}(\mathrm{III})^{9}$. The yellow colored cobalt complex and red coloured nickel complex have been extracted quantitatively using carbon tetrachloride in the $\mathrm{pH}$ range of 4-11 and 4.0-6.7 respectively. The colors of these complexes are stable and absorptions have been measured at $389 \mathrm{~nm}$ for cobalt and $495 \mathrm{~nm}$ for nickel complexes.

$\nmid$ Presented to the National Conference on Chemistry Solutions at SRM University, India 
From the literature, it is clear that the potentiometric study using TTC were scarce. So we developed potentiometric method to estimate the TTC and also insights were made in the electrode deposits, which may open up a new era in the potentiometric sensors.

\section{Experimental}

Potentiometer

Potentiometric titrations were performed with Elico (India) pH meter of model LI 120, using bright platinum electrode and saturated calomel electrode as the working and reference electrode respectively.

\section{SEM-EDAX studies}

All the adsorbed complex species on platinum electrodes were subjected to SEM-EDAX analysis for the surface study and chemical constituents. Aim and shoot methodology were performed by using Hitachi S-3400 scanning electron microscope equipped with x-ray microanalysis. Before recording the images of the adsorbed complexes on platinum electrodes, a reference imaging and EDAX analysis were performed for plain platinum electrode. The platinum electrodes were cleaned by sonication with $5 \mathrm{M}$ hydrochloric acid to remove the impurities from the electrode and rinsed with double distilled water twice to remove the acid from the electrode surface.

\section{Reagents}

All the chemicals used were of Analar grade reagents and used as received. Double distilled water was used throughout the work. Diethyl ether, hexadecylthiol, dimethylformamide, and chloroform were bought from E-Merck. Potassium hydroxide, sodium acetate and sodium carbonate were from Sisco Research Laboratories (India). Mercuric chloride was from Central Drug House (India).

\section{Solutions}

\section{Potassium salt of Hexadecyl trithiocarbonate}

The potassium salt of hexadecyltrithiocarbonate was prepared by reacting $10 \mathrm{~mL}$ hexadecyl thiol with $6 \mathrm{~mL}$ of carbon disulphide, added in drop wise in the presence of potassium hydroxide in minimum quantity of water; the contents were cooled and maintained below $5{ }^{\circ} \mathrm{C}$ with constant vigorous stirring for about half of an hour. The yellow solid obtained was filtered and washed with diethyl ether and then dried.

\section{Mercuric chloride}

$0.05 \mathrm{M}(3.3937 \mathrm{~g})$ mercuric chloride solution was prepared with double distilled water in $250 \mathrm{~mL}$.

\section{Results and Discussion}

The different types of reaction that takes place in the solution and with electrode material:

\section{Stage 1: At the electrode}

At the electrode (being more positive and anodic in nature) the HDTTC solution being more negative, interaction takes place very strongly, hence adsorption overcoming the outer and inner Helmholtz plane which lead to the formation of complex at the electrode material and is pictorially represented as (Figure 1), 

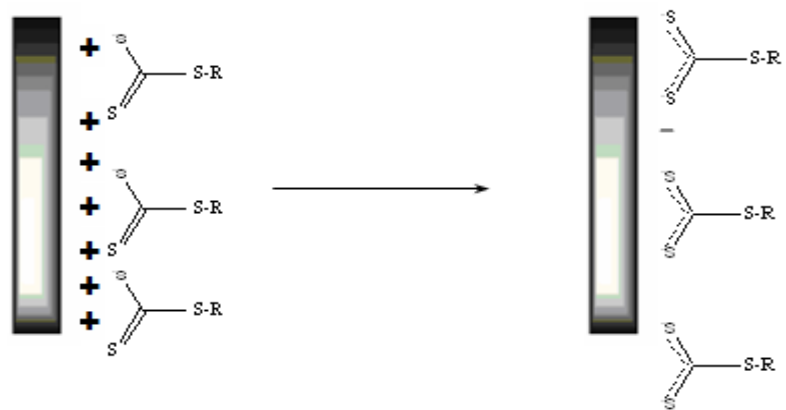

Figure 1. Pictorially representation of the formation of complex at the electrode material

Since a lone pair of electrons was available on the other sulphur atom and being in close proximity with the metal electrode, the unique cyclization (four membered ring formation on complexation) which is characteristic of dithio ligands takes place, and ultimately a dianion results following strong complexation.

\section{Stage-2: Bulk of the solution}

At the beginning of the titration with mercury ions, the mercuric ion forms complex with HDTTC available in the bulk of the solution in 1:2 (M: L) ratio (Scheme 1),

Stage-3 Interaction of mercuric ions with electrode and its surface complexes

$$
\mathrm{CH}_{3}-\left(\mathrm{CH}_{2}\right)_{14}-\mathrm{CH}_{2}-\mathrm{S}-\mathrm{C} \mathrm{S}^{-} \mathrm{K}^{+}+\mathrm{Hg}_{2}^{+} \longrightarrow\left(\mathrm{CH}_{3}-\left(\mathrm{CH}_{2}\right)_{14}-\mathrm{CH}_{2}-\mathrm{S}-\mathrm{C} \mathrm{S}^{-}\right)_{2}^{\mathrm{Sg}}
$$

\section{Scheme 1}

As the titration progressed, the available excess mercuric ions competes a place for the electrode to form the mercury HDTTC complex on the electrode. Mercuric ions plug ligands from the electrode surface owing to the higher stability of the mercury complex formed. There is a possibility for the formation of a mixed hetero metallic complex of platinum and mercury. This takes place at the surface of the electrode, and thereby making the electrode surface unavailable for sensing the ongoing reaction i.e. sensing the decrease of HDTTC or complexation. Ultimately, an electrode deposit occurs, which composed of the ligand, mercury and platinum. The electrode with the deposit on further examination with SEM and EDAX by aim and shoot method (Figures $3 a \&$ b, Table 1) reveals the presence of mercury, carbon, sulphur and a very low percentage of potassium.

\section{Potentiometric titration of hexadecyl trithiocarbonate (HDTTC) with mercuric chloride towards platinum electrode in presence of universal buffer}

The titration graphs (Figure 2) in all the $\mathrm{pH}$ show a well-defined ' $\mathrm{S}$ ' type graph. The starting potential in the lower $\mathrm{pH},(2-7)$ distributed over $50 \mathrm{mV}$ and in the higher $\mathrm{pH}$ the starting potentials lie well within $20 \mathrm{mV}$ and was very compact, distinct ' $\mathrm{S}$ ' type. As usual a strong interaction takes place between the positive electrode and the negative HDTTC at the beginning. The graph of the titration of HDTTC with mercuric ions without universal buffer exhibit a similar ehavior to that of the lower $\mathrm{pH}$ but slightly differ at the start of the titration. Initially it was dipped $120 \mathrm{mV}$ more negative than the initial potential. It indicates that as the complexation of mercuric ions progresses, it very well takes place on the electrode 
initially with the adsorbed HDTTC on to the platinum electrode. Further adsorption of HDTTC suffered a strong obstruction by the mercuric ions which led to the mercuric trithiocarbonate complex formation. Hence the potential at the higher $\mathrm{pH}(8-11)$ from the beginning of titration remained almost constant in the more negative side itself and continued to maintain up to the same well above the 1: $2(\mathrm{M}: \mathrm{L})$ equivalent. The recoveries were about $150 \%$ in case of mercuric ions with HDTTC. To account for the high recovery of mercuric ions with HDTTC can be explained. The electrode material senses the decrease in concentration of HDTTC or complexation at appropriate levels. Up to this electrode material was surrounded by dianions of HDTTC, after the complexation point, the excess mercuric ions even complexes the dianions of HDTTC, because of the preferred interaction between mercuric ions and sulphur atoms of the HDTTC. The electrode material was left as such i.e., no HDTTC on the surface of electrode. A very good inflection point was observed for mercury alone. The inflection with a gap of at least $500 \mathrm{mV}$ indicate that the titration/graph was found to be good with different inflection and sharp end point and hence recommended for quantitative estimation. But it needs some more insight. Based on the quantitation observed, besides with already existing results, the following structures are proposed.

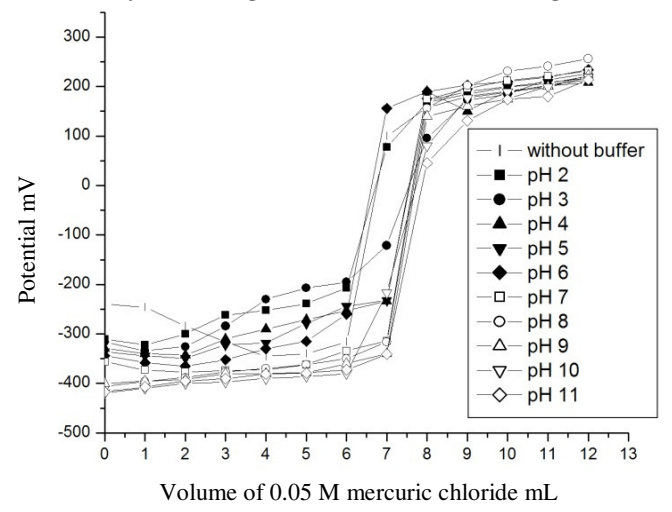

Figure 2. Titration $0.05 \mathrm{M}$ HDTTC with $0.05 \mathrm{M}$ mercuric chloride in presence of universal buffer $\mathrm{pH}(2-11)$ using platinum electrode<smiles>[R3][R]1S[As]2(S1)SC([R3])S2</smiles>

Scheme 2. Complex (I) formed with mercury

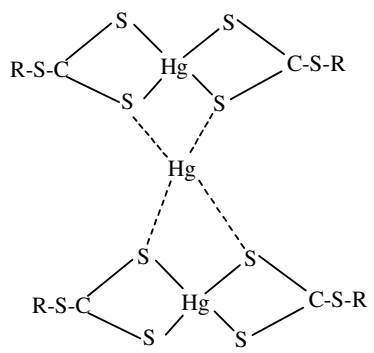

Scheme 3. Complex (II) formed with excess of mercuric ions

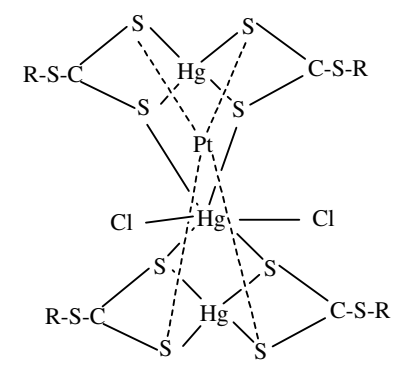

Scheme 4. Complex (III) formed on the surface of the electrode 
The differentiation between the structure I \& II (Scheme $2 \& 3$ ) can be established by two methods.

(1) By solubility of the two complex synthesized; (2) by solid state conductivity. The excess mercuric ions form 3:4 complex, which was further confirmed by solid state conductivity. The complex (I) is soluble in chloroform and the complex (II) is insoluble in chloroform. Even after all these reactions a multilayer deposition also take place indicating that after the complexation was completed, still some negative charge remained on the electrode surface which allows further adsorption leading to a thick multilayer formation on to the electrode. The SEM and EDAX confirmed the same (Figure $3 \& 4$ ). The EDAX study confirmed the presence of high amounts of mercury and platinum in the complex on the electrode followed by chlorine besides the sulphur and carbon with slightly less amount.

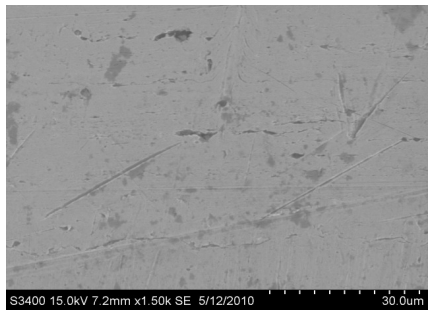

(a)

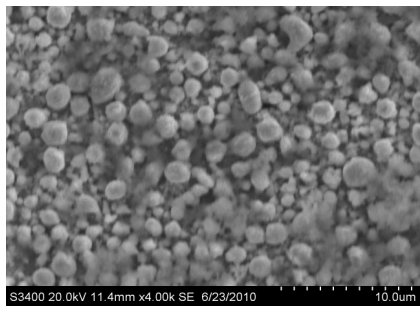

(b)

Figure 3. SEM micrographs of (a) Bare platinum electrode (b) Multilayer deposits of mercury-HDTTC complex on platinum electrode

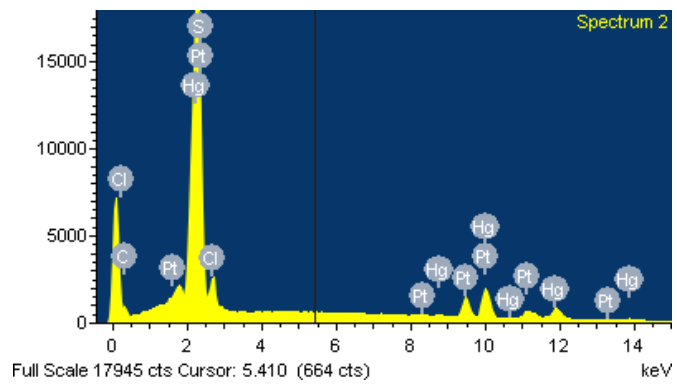

Figure 4. EDAX spectrum for HDTTC with mercuric ions on platinum electrode

Table 1. Chemical constituents present on the platinum electrode for mercury with HDTTC

\begin{tabular}{ccc}
\hline Element & Weight \% & Atomic \% \\
\hline $\mathrm{C} \mathrm{K}$ & 11.22 & 61.07 \\
$\mathrm{~S} \mathrm{~K}$ & 1.34 & 2.74 \\
$\mathrm{Cl} \mathrm{K}$ & 4.94 & 9.12 \\
$\mathrm{Pt} \mathrm{M}$ & 19.74 & 6.61 \\
$\mathrm{Hg} \mathrm{M}$ & 62.76 & 20.46 \\
\hline
\end{tabular}

Figure 5 gives the titration plots of the studies with universal buffer and mercuric ions. The figure follows the same trend as in case of zinc and cadmium. i.e., as the $\mathrm{pH}$ increases, the starting potential increases. i.e., in very much positive side. For lower $\mathrm{pH}(2-4)$ the potential was very wide (315 to $440 \mathrm{mV})$, for higher $\mathrm{pH}(5-11)$, the starting potential was compact $(460-470 \mathrm{mV})$. The potential lies in positive direction with a straight line with small increments. The graph clearly shows that the universal buffer component does not interfere with the reaction of HDTTC with mercuric ions. 


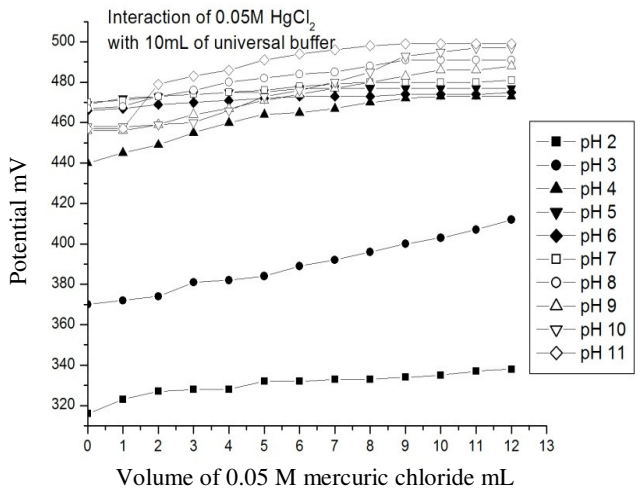

Figure 5. Titration of $0.05 \mathrm{M}$ mercuric chloride with universal buffer $\mathrm{pH}(2-11)$ using platinum electrode

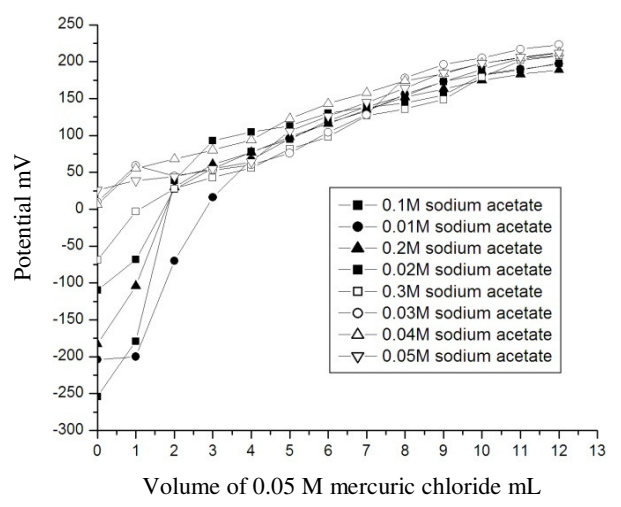

Figure 6. Titration $0.05 \mathrm{M}$ HDTTC with $0.05 \mathrm{M}$ mercuric chloride in presence of various concentrations of sodium acetate $(0.1 \mathrm{M}$, $0.01 \mathrm{M}, 0.2 \mathrm{M}, 0.02 \mathrm{M}, 0.3 \mathrm{M}, 0.03 \mathrm{M}, 0.04$ $\mathrm{M}$ and $0.05 \mathrm{M}$ ) using platinum electrode

Figure 6 shows the titration of HDTTC with mercuric ions in presence of various concentrations of sodium acetate. The shape of the graph was not desired one by using sodium acetate as the ionic and buffering agent; the quantification cannot be possible here. Figure 7 shows the titration of HDTTC with mercuric ions in presence of various concentrations of sodium carbonate. But at all other concentrations shows the quantification in the range of $50-80 \%$ only. The quantification of $\sim 100 \%$ was achieved in case of $0.2 \mathrm{M}$ sodium carbonate.

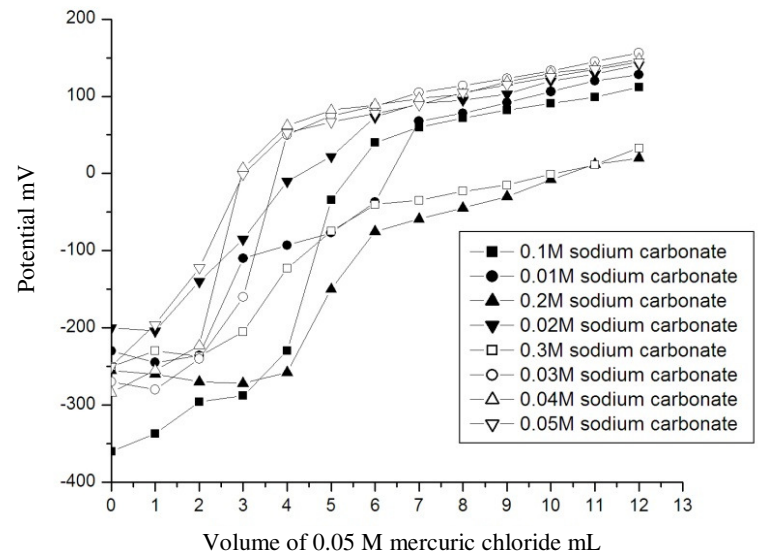

Figure 7. Titration $0.05 \mathrm{M}$ HDTTC with $0.05 \mathrm{M}$ mercuric chloride in presence of various concentrations of sodium carbonate $(0.1 \mathrm{M}, 0.01 \mathrm{M}, 0.2 \mathrm{M}, 0.02 \mathrm{M}, 0.3 \mathrm{M}, 0.03 \mathrm{M}, 0.04 \mathrm{M}$ and $0.05 \mathrm{M}$ ) using platinum electrode.

\section{Conclusion}

The multilayer deposit of the mercury-HDTTC complex on the electrode was investigated by using SEM and the elemental composition of the complex was further evidenced by EDAX. The titration of mercury with HDTTC was carried out in different $\mathrm{pH}$ and also in 
various concentrations of the sodium acetate and sodium carbonate. But the quantitative results were obtained only in the higher $\mathrm{pH}$ of the universal buffer with $150 \%$ recovery of the HDTTC. In case of all other ionic strength/monitoring agent the results were not satisfactory.

\section{References}

1. Chaudhari S and Tare V, Water Sci Technol., 1996, 34(10), 161-168.

2. Chaudhari S and Tare V, J Appl Polym Sci., 1999, 71(8), 1325-1332.

3. Kumar A, Rao N N and Kaul S N, Biores Technol., 2000, 71(2), 133-142.

4. Devdutt Chaturvedi, Amit K Chaturvedi, Nisha Mishra and Virendra Mishra Tetrahedron Lett., 2008, 49(33), 4886-4888.

5. Murray R Wood, David J Duncalf, Steven P Rannard and Sebastien Perrier, Org Lett., 2006, 8(4), 553-556.

6. Marani D, Mezzana M, Passino R and Tiravanti G, Environ Technol Lett., 1980, 1, 141-150.

7. Ali Reza Kiasat and Mehdi Fallah Mehrjardi, J Chin Chem Soc., 2008, 55, 639-642.

8. Schaffer C E, J Inorg Nucl Chem., 1958, 8, 149-154.

9. Ewald A H and Sinn E, Aust J Chem., 1968, 21, 927-938. 